\title{
Hubungan antara Emotion Focused Coping dan Kepuasan Hidup pada Mahasiswa
}

\author{
Eka Nur Maulida Sari ${ }^{1}$ \\ Fakultas Psikologi, Universitas Muhammadiyah Malang \\ e-mail: ${ }^{1}$ ekanurms97@gmail.com
}

\begin{abstract}
Students have responsibilities and roles in college, the adaptation process that occurs, makes students face many problems in achieving their goals and life satisfaction. Late adolescence towards early adulthood makes emotional more dominant in overcoming the problem, so that emotion focused coping has an important role in regulating emotion when face problem to proceed towards solving problems in achieving life satisfaction. This study aims to determine the correlation between emotion focused coping and students' life satisfaction. This study designed as correlational quantitative. The subject involved in this study were 650 students. The sampling technique used was proportionate stratisfied random sampling. The data collection instruments used were emotion focused coping scale and life satisfaction scale. The data were analyzed by using product moment correlation. The result of this study indicates that there is a significant correlation between emotion focused coping and life satisfaction ( $p=0.000, r=0.346)$. The effective contribution of emotion focused coping variables to life satisfaction is $12 \%$.
\end{abstract}

\section{KEYWORDS emotion focused coping, life satisfaction, college students}

CITATION Sari, E.N.M. (2019). Hubungan antara emotion focused coping dan kepuasan hidup pada mahasiswa. Cognicia, 7,(1), 95-111.

Mahasiswa merupakan sebutan untuk orang yang menjalani pendidikan di perguruan tinggi, yang memiliki peran tersendiri sebagai agent of change, agent of social control and iron stock. Pada usia perkembangan mahasiswa terjadi pada masa dewasa awal, dimana perkembangan berada pada sikap tergantung (dependence) terhadap orang tua ke arah kemandirian (independence), memiliki minat seksual, perenungan diri, dan menemukan kelompok sosial yang sesuai (Hurlock, 2009). Mahasiswa dituntut untuk mempunyai wawasan yang kritis, cerdas dalam berpikir dan mempunyai rencana melakukan sesuatu yang diinginkan (Siswoyo, 2007).

Dalam kehidupan universitas, mahasiswa diharuskan untuk menyesuaikan dengan rutinitas akademik yang lebih menuntuk dan sibuk (Essel \& Owusu, 2017). Mereka harus mengambil keputusan sulit antara untuk memilih keinginan bersenangsenang atau kuliah, mengelola hubungan dengan orang lain, mempunyai masalah ketika penyelesaian tugas individu, proyek besar dan tugas akhir (Wright, 2003). Penelitian yang dilakukan oleh Pyhalto, Toom, Stubb \& Lonka (2015) melaporkan tantangan yang dihadapi oleh mahasiswa meliputi dari proses mereka sebagai orang yang terpelajar, memiliki keahlian, dan menjadikan dirinya dapat berguna di lingkungan sekitar. Permasalahan lain yang sering dihadapi seperti masalah keuangan, kecemasan, takut gagal dan gangguan tidur yang dapat memiliki dampak negatif pada 
pandangan kepuasan hidup mereka jika tidak mengelola diri dengan baik (Stevenson \& Harper, 2016).

Proses adaptasi mahasiswa dapat dialami oleh mereka yang berasal dari luar daerah. Mahasiswa yang berbeda daerah tempat tinggal mengalami berbagai kendala seperti kurangnya pemahaman bahasa yang di pakai untuk bersosialisasi dan diskriminasi yang didapat akibat dari berbedanya penampilan, berbicara bahkan gaya hidup. Hal ini di seperti penelitian yang dilakukan oleh Li dan Campbell (2006), bahwa kesulitan seperti berbeda bahasa, budaya, gaya bicara, kurangnya pemahaman norma, dan pandangan mahasiswa dapat mempengaruhi tingkat kepuasan hidup mereka ketika di perkuliahan, akibatnya penyesuaian diri yang kurang baik, akan berdampak pada prestasi dan tidak puasnya terhadap hidup.

Berdasarkan data penelitian yang dilakukan oleh Fajrina dan Kurniawan (2012), menemukan bahwa adanya permasalahan mengenai kepuasan hidup pada mahasiswa, terdapat $2 \%$ mahasiswa yang menyatakan "selalu" merasa sudah mendapatkan hal yang sesuai dengan keinginan dalam hidupnya, sebanyak 3,1\% mahasiswa menyatakan "selalu" kehidupannya mendekati ideal dan bertindak untuk melakukan perubahan dalam hidupnya, sebanyak 4,1\% mahasiswa "selalu" merasa puas dengan kehidupannya dan 6,1\% mahasiswa menyatakan "selalu" merasa hidupnya sangat baik. Dari hal tersebut menunjukkan pada dasarnya kepuasan hidup ialah evaluasi subjektif seseorang terhadap apa yang paling penting dalam hidup, tujuan dan harapanya (Frisch, 1998).

Berdasarkan penelitian yang dilakukan oleh Ryan (2013), melakukan penyelidikan dalam memahami lebih spesifik permasalahan yang dialami mahasiswa, baik secara akademis maupun non-akademis yang berpengaruh terhadap kepuasan hidup mahasiswa. Beberapa permasalahan yang dialami mahasiswa, seperti pergaulan bebas (penggunaan narkoba dan minuman keras), lingkungan yang tidak mendukung, beban akademik (materi yang susah dipahami, persaingan prestasi dan sistem perkuliahan), dan perilaku anti sosial yang dapat mengakibatkan dampak tersendiri bagi mahasiswa. Bahkan yang dapat ditimbulkan dari permasalahan mahasiswa tersebut jika tidak dipahami dengan baik akan mengakibatkan banyaknya masalah yang akan berpengaruh terhadap peran mahasiswa di perkuliahan. Jika peran tersebut tidak di jalankan dengan baik maka akan mempengaruhi mahasiswa dalam mencapai kepuasan hidupnya.

Mahasiswa yang merasa cukup dan mampu dalam menerima yang telah dimiliki dapat membentuk sikap seseorang untuk mencapai kepuasan hidup. Proctor, Linley \& Malby (2008) mengatakan kepuasan hidup dapat menguntungkan dalam kehidupan remaja dan berfungsi sebagai penguat untuk melawan dampak lingkungan yang negatif, permasalahan dan gangguan psikologis. Jika terjadi kepuasan hidup yang rendah pada remaja menuju dewasa, muncul berbagai masalah yang terjadi seperti masalah kesehatan, penggunaan obat terlarang, kekerasan, perilaku agresi dan perilaku seksual (Valois, 2004). Sebaliknya, yang memiliki kepuasan hidup yang tinggi, memiliki nilai pelajaran yang baik dan kesejahteraan sosial (Suldo, 2008).

Kepuasan hidup merupakan bagian dari subjective well being, yang mengacu pada sebuah aspek kehidupan dari seseorang yang penting dalam kehidupan individu. Secara umum, kepuasan hidup merujuk pada seseorang yang berpuas hati dengan 
yang didapat saat ini, aspeknya secara kognitif dapat diukur oleh individu terhadap dirinya (Amat \& Mahmud, 2009). Kepuasan hidup adalah total dari pandangan seseorang dari berbagai aspek hidupnya dalam lingkup keluarga, lingkungan dan masyarakat dan ukuran gabungan dari fisik, mental dan kesejahteraan sosial yang dirasakan oleh setiap orang atau kelompok individu, yang meliputi kebahagiaan, kepuasan, kesehatan, keluarga, pekerjaan, situasi keuangan, rasa memiliki dan kepercayaan orang lain. Oleh karena itu orang yang mempunyai kepuasan hidup yang tinggi memiliki penyesuaian diri serta kebahagiaan atas situasi kehidupannya dan sebaliknya (Kang \& Princy, 2013).

Sebagai sikap positif terhadap kehidupan, kepuasan hidup dikaitkan dengan perilaku dan sikap prososial lain seperti harga diri dan dukungan sosial, serta berhubungan negatif dengan depresi dan keinginan bunuh diri (Zhang, 2013). Perbedaan gender dapat mempengaruhi kepuasan hidup mahasiswa di perkuliahan, dimana perempuan menyatakan lebih banyak mendapatkan dukungan sosial tetapi lebih banyak mengalami tekanan dan kurang merasa akan kepuasan hidup daripada laki-laki (Jenkins, 2013). Oleh karena itu, mahasiswa akan memiliki kepuasan hidup pada kondisi kehidupan mereka ketika masuk ke perkuliahan yang akan menjadi acuan bahwa individu secara sadar atau tidak akan memilih untuk membandingkan dengan keadaannya saat ini.

Penyesuaian positif pada mahasiswa salah satu indikatornya adalah kepuasan hidup yang mempengaruhi dinamika perkuliahan. Kepuasan hidup ialah salah satu dari tiga komponen kesejahteraan subjektif yang setara dengan kebahagiaan dan evaluasi kognitif dari kehidupan individu (Civitci, 2015). Sebagai yang lebih stabil daripada komponen afektif, kepuasan hidup memungkinkan dapat melakukan evaluasi jangka panjang tanpa memperhatikan waktu tertentu (Eid \& Diener, 2004). Selanjutnya, kepuasan hidup sangat terkait dengan indikator kualitas objektif kehidupan seperti kesehatan, status keuangan, kebebasan, dan hiburan (Diener \& Suh, 1997). Akibatnya kepuasan hidup yang dirasakan berdasarkan pada hasil evaluasi terkait kehidupannya sendiri dan tentang kualitas dari kepuasan hidupnya.

Dari hal tersebut, bahwa kepuasan hidup menjadi bagian penting dalam perjalanan kehidupan, tidak terkecuali mahasiswa yang mempunyai berbagai permasalahan di perkuliahan menjadikan mahasiswa berhak dalam mendapatkan kepuasan hidup selain untuk menjalankan tugas dan tanggung jawabnya.

Kepuasan hidup pada mahasiswa terkait masa perkembangannya yang berada di fase transisi kehidupan, yakni ketika seseorang mengalami masa perpindahan dari sekolah tinggi ke perguruan tinggi untuk menuju dewasa (Duffy, Bogdan \& Steger, 2008 ). Menurut Lounsbury, Saudargas, Gibson, \& Leong, (2005) bahwa ketika mahasiswa berada di fase transisi menuju dewasa mereka mulai memiliki prediksi yang baik saat kuliah maupun terkait seberapa puasnya mereka dengan pengalamannya, dapat dipahami kepuasan hidup mahasiswa selama masa transisi dapat memberikan wawasan mengenai hasil psikologis dan perguruan tinggi terkait di masa depan.

Berdasarkan pengertian mengenai kepuasan hidup pada mahasiswa bahwa kepuasan hidup terkait dengan berbagai karakteristik setiap individu dan interaksi dengan lingkungan. Adapun hal yang mempengaruhi kepuasan hidup berdasarkan 
perbedaan individual diantaranya evaluasi diri positif, karakteristik positif, berkeyakinan tinggi, pengendalian emosi, kemampuan interaksi sosial, persepsi diri, optimisme, kesehatan, kesejahteraan, tingkat stres dan jenis kelamin (Lewis, 2011). Oleh karena itu, kepuasan hidup membentuk sikap yang mempengaruhi sifat ataupun karakteristik seseorang termasuk mahasiswa yang masa perkembangannya berada di masa transisi menuju dewasa awal sehingga pengaruh yang terjadi akan berdampak dalam membentuk karakteristik kepuasan hidupnya, dengan melalui proses berupa pengalamannya selama kuliah atau menghadapi permasalahan yang melibatkan diri sendiri ataupun lingkungan sekitar. Berdasarkan dari beberapa hal yang mempengaruhi kepuasan hidup didapat salah satunya adalah mengenai pengendalian emosi, karena kepuasan hidup secara keseluruhan diperkirakan dapat mempengaruhi respon emosi dan perilaku dalam kaitannya dengan peristiwa kehidupan yang akan datang (Diener, Suh, Lucas \& Smith, 1999).

Menurut Folkman (Wulandari, 2012) coping merupakan usaha individu untuk mengatur jarak diantara tuntutan dari individu itu sendiri atau lingkungan dengan sumber daya yang mereka gunakan untuk menghadapi situasi permasalahan. Tujuan dari coping adalah agar setiap individu yang mengalami stres, dapat mengatur sedemikian rupa agar dapat mengatur stres yang dikeluarkan menjadi terkontrol baik. Coping terbagi dalam dua cara, yaitu (1) coping yang berfokus pada permasalahan atau yang disebut problem focused coping, (2) coping yang berfokus pada emosi atau yang disebut emotion focused coping. Problem focused coping ialah cara untuk menyelesaikan tuntutan atau tanggung jawab internal maupun lingkungan dengan melakukan suatu aksi, sedangkan emotion focused coping ialah usaha dalam mengurangi perasaan tertekan yang tidak menyenangkan dengan melakukan cara tertentu yang melibatkan emosi.

Berdasarkan dari penelitian oleh Ryan (2013) pada mahasiswa di Irlandia, menemukan bahwa dampak mahasiswa yang melakukan strategi coping dalam kehidupannya menghasilkan kepuasan hidup. Dimana strategi coping yang digunakan adalah emotion focused coping menunjukkan korelasi negatif yang lemah terhadap kepuasan hidup. Untuk memperdalam hasil tersebut, dibagi lagi menjadi sub kategori avoidant focused coping dan active focused coping, masing-masing dari sub kategori memberikan hasil yang berbeda. Bahwa avoidant focused coping secara signifikan berhubungan dengan stres, karena hasil yang menunjukkan mahasiswa lebih banyak menggunakan avoidant focused coping akibat dari tingkat stres yang dirasakan tinggi. Berbeda halnya dengan active focused coping yang tidak memiliki hubungan dengan stres yang dirasakan pada mahasiswa, karena mahasiswa laki-laki memiliki tingkat kepuasan hidup yang lebih tinggi dari pada mahasiswa perempuan. Hal tersebut menunjukkan bahwa terdapat perbedaan hasil kepuasan hidup yang dipengaruhi oleh gender, karena pria lebih cenderung mengambil tindakan langsung dan terlibat dalam penyelesaian masalah dari pada perempuan. Namun kembali lagi terhadap kegunaan dan kesuksesan penggunaan strategi coping yang akan digunakan serta akan tercermin tingkat kepuasan hidupnya.

Baqutayan (2012), berpendapat bahwa strategi coping digunakan dalam berbagai cara pengaturan emosi, proses berfikir dan berperilaku. Hal tersebut dibentuk dari respon psikologis seseorang terhadap masalah yang muncul, peristiwa dan tujuan 
serta hasil yang mereka dapatkan tergantung pada konteks sosial dan hubungan interpersonal. Para mahasiswa yang memiliki tanggung jawab dalam melakukan kegiatan, berkompetensi akademik dan hubungan dengan teman sebaya, dimana hal tersebut tantangan kehidupan nyata yang mengarah pada tekanan mental mahasiswa itu sendiri.

Berdasarkan penelitian yang dilakukan oleh Saptoto (2010), bahwa ada hubungan antara emotion focused coping terhadap kecerdasan emosi. Kecerdasan emosi digunakan dalam mengambil keputusan atau tindakan. Bagi seseorang yang memiliki kecerdasan emosional baik maka dalam pengambilan tindakan akan tepat meskipun saat keadaan kritis dan begitu sebaliknya. Setiap permasalahan tentunya akan diselesaikan sesuai dengan kemampuan individu itu sendiri, melakukan dengan cara langsung berfokus pada masalahnya atau melibatkan emosi. Jika mahasiswa memiliki permasalahan yang dapat ditangani dengan baik menggunakan strategi yang dipakai maka mahasiswa tersebut memiliki kecerdasan emosi yang mempengaruhi pula dengan kepuasan hidupnya.

Menurut Mappiare (1982), ketika menghadapi permasalahan yang dialami oleh mahasiswa, kebanyaan dari mereka menggunakan cara yang emosional, karena masa tersebut dipenuhi perasaan yang bergejolak dan peka terhadap rangsangan negatif, akibatnya mahasiswa menggunakannya untuk meminimalkan atau menghilangkan tekanan. Pemakaian emotional focused coping cenderung akan membawa seseorang pada situasi tertekan, memiliki kecemasan yang berlebih, dan merasa bersalah, karena cara ini mengarah pada tindakan dalam menyeimbangkan afeksi. Mahasiswa yang menggunakan cara ini akan melakukan tindakan secara emosional berupa mencari dukungan sosial, penolakan dari masalah yang ditandai perilaku merokok dan merusak diri (Hestiningrum, 2012).

Mahasiswa ketika menjalani proses untuk belajar di perguruan tinggi, mereka juga menjalani proses perkembangannya menuju tahap dewasa, namun tidak semua mahasiswa dapat melalui proses tersebut dengan baik, hal ini menyebabkan mahasiswa cenderung tidak puas dengan kehidupannya, kondisi mahasiswa yang tidak puas dengan kehidupannya dapat memunculkan masalah berupa kesulitan dalam mengelola atau mengontrol emosi ketika terjadi masalah (Park, Peterson, \& Seligman, 2004). Pada masa mahasiswa yang berada di usia 18-25 tahun, bahwa seseorang memiliki resiko yang tinggi untuk lebih emosional dibandingkan dengan usia lainnya (Ehrlich dan Isaacowitz, 2002).

Berbagai permasalahan yang datang pada mahasiswa sebagai seorang akademisi perkuliahan dan faktor lainnya seperti lingkungan dan pertemanan, mengakibatkan rentannya untuk terkena masalah yang mengakibatkan stres, maka perlunya penanganan atau strategi dalam menghadapi setiap tekanan yang dating (Deniz, 2006). Terutama pada usia transisi menuju dewasa awal yang sedang dialami oleh mahasiswa, sebagian besar lebih menggunakan emosi dalam mengatasi masalahnya (Saklofske, Austin, Mastoras, Beaton \& Osborne, 2012). Sehingga, penggunaan emotion focused coping pada mahasiswa ketika menghadapi masalah perlunya ditangani dengan baik dan tepat agar masalah yang terjadi diharapkan membuat mahasiswa dapat mengatasi permasalahannya, merasa puas atau bermakna akan keadaan dirinya karena dapat mengatasi tekanan dengan kemampuannya dalam mengendalikan emosi. 
Penelitian yang dilakukan oleh Ryan (2013) bahwa emotion focused coping menunjukkan hasil yang signifikan dengan korelasi negatif yang lemah terhadap kepuasan hidup pada mahasiswa di Irlandia, maksudnya dari kedua variabel tersebut tidak terlalu saling berkaitan kuat antara emotion focused coping dan kepuasan hidup. Selain itu, keterbatasan penelitian yang diungkapkan bahwa mayoritas pengumpulan data dalam penelitian ini berlangsung sepanjang bulan januari, bagi perguruan tinggi pada bulan tersebut adalah bulan untuk ujian yang kemungkinan bahwa para mahasiswa yang mempersiapkan ujian merasa sangat tertekan serta mahasiswa yang dijadikan subjek tidak terdapat keterangan mengenai semester yang ditempuh dan pengambilan sampel dalam penelitian sebelumnya menggunakan teknik convenience sampling atau incidental sampling.

Sehingga dalam penelitian ini, ingin melakukannya pada waktu semester genap atau setelah para mahasiswa menyelesaikan ujian akademiknya, agar didapatkan perbandingan hasil antara penelitian sebelumnya dengan yang akan diteliti nanti dan penentuan subjek juga dari peneliti ingin menggunakan subjek pada angkatan tahun 2015 dan 2016 atau sekitar semester 8 dan 6 dengan alasan bahwa pada angkatan tersebut sudah pernah merasakan berbagai dinamika perkuliahan yang dianggap dapat dijadikan subjek dalam penelitian. Pada angkatan tersebut berkisar usia $19-23$ tahun atau berada pada tahap perkembangan dewasa awal (Santrock, 2010). Pada tahap perkembangan ini, mahasiswa mulai mengembangkan ideologi dalam membentuk pandangan hidup, mulai mempertanyakan hal yang penting untuk dirinya, mulai berkomitmen terhadap suatu nilai tertentu, sehingga nilai tersebut yang akan menjadi dasar untuk mengembangkan dalam tujuan hidup (Arnett, 2015).

Berdasarkan penjelasan diatas, peneliti ingin melakukan penelitian untuk mengetahui apakah terdapat hubungan antara emotional focused coping dan kepuasan hidup pada mahasiswa. Tujuan dari penelitian ini adalah untuk mengetahui hubungan antara emotional focused coping dan kepuasan hidup pada mahasiswa. Manfaat penelitian secara teoritis adalah agar penelitian ini dapat memberikan sumbangan pemikiran dalam pengembangan keilmuan psikologi, serta manfaat secara praktis bagi mahasiswa adalah untuk meningkatkan pengetahuan mahasiswa terkait penanganan masalah menggunakan strategi coping dan mengetahui bagaimana cara dapat memperoleh kepuasan hidup dalam menjalani berbagai permasalahan sebagai seorang mahasiswa, manfaat bagi peneliti adalah menambah wawasan ilmu pengetahuan terkait emotion focused coping dan kepuasan hidup pada mahasiswa, serta manfaat bagi lembaga adalah agar dapat mengembangkan intervensi terkait dengan hal-hal atau kegiatan yang dapat melatih penanganan mahasiswa dalam menghadapi masalah agar mencapai kepuasan hidup.

\section{METODE}

Pada penelitian ini, yang ingin diteliti adalah mengenai adanya ada hubungan dengan masing-masing variabel antara emotion focused coping dan kepuasan hidup pada mahasiswa, agar menjawab pertanyaan pada penelitian ini adalah dengan menggunakan pendekatan metode kuantitatif. Menurut Sugiyono (2005), pendekatan 
kuantitatif ialah karakteristik dari suatu variabel yang nilainya dinyatakan dalam bentuk angka, kemudian penelitian tersebut menggunakan statistik beserta analisanya.

Penelitian ini menggunakan penelitian kuantitatif korelasional, yakni untuk mempelajari hubungan dua variabel atau lebih, yakni sejauh mana variasi dalam satu variabel yang berhubungan dengan variasi atau variabel lain (Suryabrata, 2005). Alasan penelitian menggunakan penelitian korelasional adalah bertujuan untuk mengetahui seberapa kekuatan suatu hubungan antara dua variabel penelitian, yaitu variabel emotion focused coping dan kepuasan hidup.

Populasi yang diambil dari penelitian ini adalah mahasiswa secara umum yang berkuliah di Universitas Muhammadiyah Malang angkatan 2015 dan 2016 atau semester 8 dan 6. Pengambilan sampel menggunakan teknik probability sampling, yaitu teknik pengambilan sampel yang memberikan peluang yang sama bagi setiap unsur populasi untuk dipilih menjadi anggota sampel (Sugiyono, 2011).

Jenis probability sampling yang digunakan adalah proportionate stratisfied random sampling, yaitu cara pengambilan sampel populasi yang mempunyai anggota yang tidak homogen dan berstrata secara proporsional dari setiap elemen populasi dan dilakukan secara random (Sugiyono, 2005). Berdasarkan hal tersebut, sampel yang akan diambil dalam penelitian ini adalah subjek dengan kriteria mahasiswa yang berkuliah di Universitas Muhammadiyah Malang angkatan 2015 dengan jumlah mahasiswa sebanyak 5675 orang dan 2016 dengan jumlah mahasiswa sebanyak 6468 orang. Adapun jumlah sampel yang ada dalam penelitian ini akan disesuaikan dengan total mahasiswa setiap angkatannya dengan presentasi batas kesalahan pada penelitian sosial maksimal sebesar $5 \%$ atau dengan taraf keakuratan data sekitar $95 \%$, yang berarti semakin besar jumlah sampel maka semakin kecil peluang kesalahan generalisasi (Sekaran, 2006 ). Sehingga subjek yang digunakan untuk angkatan 2015 sebanyak 327 orang dan angkatan 2016 sebanyak 323 orang atau dengan total subjek sekitar 650 orang mahasiswa di Universitas Muhammadiyah Malang.

Ada dua variabel yang diteliti dalam penelitian ini adalah emotional focused coping dan kepuasan hidup pada mahasiswa. Variabel independen (bebas) dalam penelitian ini adalah emotional focused coping, merupakan strategi penanganan tekanan dengan cara seseorang memberikan reaksi terhadap keadaan tekanan dengan cara emosional sebagai bentuk dalam penyelesaian masalah. Metode pengumpulan data dari variabel emotional focused coping menggunakan instrumen strategi emotion focused coping yang diadaptasi dari Adimas (2016) yang disusun berdasarkan dari aspek strategi emotion focused coping dari Lazarus dan Folkman (1984). Berdasarkan dari hasil try out yang dilakukan indeks validitas diantara 0,211 - 0,554, sedangkan reliabilitasnya sebesar 0,770 dan jumlah item sebanyak 13 butir.

Instrumen dari emotional focused coping terdiri dari 13 item yang terdiri 4 pilihan reaksi jawaban, yakni SS = Sangat Setuju, S = Setuju, TS = Tidak Setuju, STS = Sangat Tidak Setuju. Masing-masing item dari variabel emotional focused coping merupakan item yang favorable. Instrumen dalam penelitian dibuat berdasarkan dari 5 aspek variabel emotional focused coping yaitu (1) distancing yang berjumlah 3 item, (2) escape avoidance berjumlah 3 item, (3) self control berjumlah 1 item, (4) accepting responsibility yang berjumlah 2 item, (5) positive reappraisal berjumlah 4 item. 
Sedangkan variabel dependen (terikat) dalam penelitian ini adalah kepuasan hidup, merupakan suatu proses penilaian kognitif yang membandingkan hal yang terjadi dalam hidup seseorang dengan standar yang dimiliki atau penilaian terhadap kualitas hidup sesuai dengan kriteria yang dipilih oleh individu tersebut. Metode pengumpulan data dari variabel kepuasan hidup menggunakan instrumen kepuasan hidup yang itemnya diadopsi dari Kusumawati (2016), disusun berdasarkan dari komponen life satisfaction yang sesuai diungkapkan oleh Diener (1984), bahwa semakin tinggi skor total, maka kepuasan hidup semakin tinggi pula. Berdasarkan dari hasil try out yang dilakukan indeks validitas diantara 0,196-0,638, sedangkan reliabilitasnya sebesar 0,884 dan jumlah item sebanyak 28 item dengan skala yang ada sebelumnya kemudian dikembangkan berdasarkan aspek.

Instrumen kepuasan hidup terdiri dari 28 item yang menggunakan 4 pilihan reaksi jawaban, yakni SS = Sangat Setuju, S = Setuju, TS = Tidak Setuju, STS = Sangat Tidak Setuju. Masing-masing item dari variabel kepuasan hidup terdapat 22 item favorable. dan 6 item non-favorable. Instrumen dalam penelitian dibuat berdasarkan dari 5 aspek variabel kepuasan hidup yaitu (1) keinginan untuk mengubah kehidupan yang berjumlah 6 item, (2) kepuasan terhadap kehidupan saat ini yang berjumlah 6 item, (3) kepuasan hidup di masa lalu yang berjumlah 5 item, (4) kepuasan hidup di masa mendatang yang berjumlah 4 item, dan (5) penilaian terhadap kehidupan yang berjumlah 7 item.

Secara umum langkah yang akan dilakukan dalam penelitian ini adalah tahap persiapan, tahap pelaksanaan dan tahap analisa. Pada tahap persiapan yakni dengan menentukan perumusan masalah, menentukan variabel dalam penelitian, kemudian melakukan kajian literasi dalam mendapatkan gambaran dan landasan yang teoritis. Selanjutnya menentukan indikator dalam menyiapkan skala penelitian yaitu skala emotion focused coping dan kepuasan hidup serta melakukan try out pada tanggal 11 - 13 Januari 2019 pada Mahasiswa Universitas Muhammadiyah Malang sekitar 116 orang. Setelah dilakukan try out untuk memperoleh validitas dan reliabilitas skala yang dipakai, kemudian peneliti mempersiapkan kembali skala yang akan diuji setelah dilakukan beberapa penyisihan item saat try out untuk dilakukan pengambilan data kembali.

Tahap pelaksanaan, peneliti melakukan survey atau meminta data untuk mendapatkan informasi mengenai jumlah mahasiswa yang aktif berkuliah di Universitas Muhammadiyah Malang melalui Biro Administrasi Akademik (BAA) Universitas Muhammadiyah Malang. Hal ini bertujuan agar dapat mempermudah peneliti dalam menyebarkan skala dan menentukan jumlah subjek yang akan diteliti, kemudian peneliti mulai menyebarkan skala melalui penyebaran secara online maupun offline pada tanggal 29 Januari - 22 Februari 2019 dengan karakteristik yangtelah peneliti tentukan yakni mahasiswa Universitas Muhammadiyah Malang, angkatan 2015 dan 2016 pada semua fakultas.

Pada tahap analisa, setelah mendapatkan data sesuai dengan jumlah subjek yang ditentukan, peneliti melakukan analisa data untuk mengetahui hubungan antara dua variabel yang diteliti yaitu menggunakan analisa korelasi product moment, yang sesuai dengan tujuan penelitian untuk mencari hubungan dan dalam membuktikan hipotesa mengeni hubungan antara dua variabel (Sugiyono, 2011). 


\section{HASIL}

Subjek yang berpartisipasi dalam penelitian ini dan sesuai dengan kriteria yang telah ditentukan oleh peneliti untuk kebutuhan penelitian sebanyak 650 subjek. Berikut deskripsi subjek penelitian:

Tabel 1. Deskripsi subjek penelitian

\begin{tabular}{ccc}
\hline Kategori & Frekuensi & Presentase \\
\hline $\begin{array}{c}\text { Jenis Kelamin } \\
\text { Laki-laki }\end{array}$ & 246 & \\
Perempuan & 404 & $37,8 \%$ \\
\hline Usia & & $62,2 \%$ \\
19 Tahun & 65 & $10 \%$ \\
20 Tahun & 183 & $28,2 \%$ \\
21 Tahun & 223 & $34,3 \%$ \\
22 Tahun & 149 & $22,9 \%$ \\
23 Tahun & 30 & $4,6 \%$ \\
\hline Angkatan & & \\
2015 & 335 & $51,5 \%$ \\
2016 & 315 & $48,5 \%$ \\
\hline
\end{tabular}

Tabel 1 menunjukkan subjek yang berpartisipasi dalam penelitian ini berjumlah 650 mahasiswa. Subjek laki-laki sebanyak 246 orang $(37,8 \%)$ dan subjek perempuan sebanyak 404 orang (62,2\%). Pada usia 19 tahun sebanyak 65 orang (10\%), usia 20 tahun sebanyak 183 orang (28,2\%), usia 21 tahun sebanyak 223 orang (34,3\%) dan usia 22 tahun sebanyak 149 orang (22,9\%), usia 23 tahun sebanyak 30 orang $(4,6 \%)$, sedangkan subjek dengan angkatan 2015 sebanyak 335 orang (51,5\%) dan angkatan 2016 sebanyak 315 orang (48,5\%). Berdasarkan uji kolmogorov-smirnov, data dikatakan normal apabila nilai signifikan di atas 0,05. Dari hasil uji normalitas yang dilakukan pada kedua variabel dikatakan normal karena nilai signifikan sebesar 0,274 $(\mathrm{p}>0,05)$.

Hasil menunjukkan data kategori variabel emotion focused coping dan kepuasan hidup dibagi menjadi dua kategori yaitu kategori tinggi untuk emotion focused coping sebanyak 352 orang dengan presentasi 54,15\%, dan pada kategori rendah sebanyak 298 orang dengan presentasi 45,85\%. Pada variabel kepuasan hidup dibagi menjadi dua kategori yaitu tinggi dengan nilai sebanyak 326 orang dengan presentasi sebesar $50,15 \%$ dan pada kategori rendah sebanyak 324 orang dan presentasi sebesar $49,85 \%$.

Hasil pada subjek laki-laki yang memiliki emotion focused coping tinggi sebanyak 111 orang dan yang rendah sebanyak 135 orang, subjek perempuan yang memiliki emotion focused coping tinggi sebanyak 214 orang dan yang rendah sebanyak 163 orang. Subjek laki-laki yang memiliki kepuasan hidup yang tinggi sebanyak 109 orang dan yang memiliki kepuasan hidup yang rendah sebanyak 137 orang, sedangkan untuk subjek perempuan yang memiliki kepuasan hidup yang tinggi sebanyak 217 orang dan yang memiliki kepuasan hidup yang rendah sebanyak 187 orang.

Hasil pada subjek yang memiliki emotion focused coping tinggi di usia 19 tahun sebanyak 30 orang, usia 20 tahun sebanyak 98 orang, usia 21 tahun sebanyak 131 orang, 
usia 22 tahun sebanyak 76 orang dan usia 23 tahun sebanyak 17 orang. Subjek yang memiliki emotion focused coping yang rendah di usia 19 tahun sebanyak 35 orang, usia 20 tahun sebanyak 85 orang, usia 21 tahun sebanyak 92 orang, usia 22 tahun sebanyak 73 orang dan usia 23 tahun sebanyak 13 orang. Subjek yang memiliki kepuasan hidup tinggi di usia 19 tahun sebanyak 31 orang, usia 20 tahun sebanyak 90 orang, usia 21 tahun sebanyak 121 orang, usia 22 tahun sebanyak 71 orang dan usia 23 tahun sebanyak 13 orang, sedangkan subjek yang memiliki kepuasan hidup yang rendah di usia 19 tahun sebanyak 34 orang, usia 20 tahun sebanyak 93 orang, usia 21 tahun sebanyak 102 orang, usia 22 tahun sebanyak 78 orang dan usia 23 tahun sebanyak 17 orang.

Skor subjek yang memilliki kategori emotion focused coping tinggi angkatan 2015 sebanyak 179 orang dan angkatan 2016 sebanyak 173 orang, sedangkan yang rendah untuk angkatan 2015 sebanyak 156 orang dan angkatan 2016 sebanyak 142 orang. Subjek dengan kategori kepuasan hidup tinggi angkatan 2015 sebanyak 169 orang dan angkatan 2016 sebanyak 157 orang, sedangakan yang rendah untuk angkatan 2015 sebanyak 166 orang dan angkatan 2016 sebanyak 158 orang. Berdasarkan skor koefisien korelasi yang dihasilkan pada tabel 6, dapat disimpulkan bahwa ada hubungan antara emotion focused coping dengan kepuasan hidup pada mahasiswa dengan taraf signifikansi sebesar 5\%. Hubungan emotion focused coping dan kepuasan hidup signifikan karena nilai signifikansi yang ditunjukkan yaitu 0,000 artinya lebih kecil dari taraf signifikasi yang digunakan yaitu $0,05(0,000<0,05)$. Selain itu, arah korelasi kedua variabel adalah positif yaitu 0,346 maka korelasi kedua variabel bersifat searah. Hasil ini menunjukkan bahwa semakin tinggi emotion focused coping maka kepuasan hidup semakin baik. Koefisien determinasi (r2) variabel emotion focused coping berdasarkan hasil analisa data adalah sebesar 0,120 yang berarti sumbangan efektif dari emotion focused coping terhadap kepuasan hidup pada mahasiswa sebesar $12 \%$ sedangkan pengaruh faktor lain terhadap kepuasan hidup sebesar $88 \%$.

\section{DISKUSI}

Berdasarkan penelitian yang telah dilakukan, hasil menunjukkan bahwa terdapat hubungan antara emotion focused coping dan kepuasan hidup pada mahasiswa. Hasil Penelitian ini menunjukkan bahwa semakin tinggi skor emotion focused coping maka semakin tinggi kepuasan hidup pada mahasiswa. Sebaliknya, semakin rendah emotion focused coping maka semakin rendah kepuasan hidup pada mahasiswa.

Dari hasil penelitian yang telah dilakukan pada variabel emotion focused coping memiliki presentase sebesar $54,2 \%$ sedangkan pada variabel kepuasan hidup memiliki presentase sebesar 50,2\%. Akan tetapi dari hasil penelitian, didapatkan hasil yang memiliki ketidaksinambungan antara emotion focused coping dengan kepuasan hidup yang apabila seharusnya semakin tinggi tingkat emotion focused coping maka semakin tinggi tingkat kepuasan hidupnya. Frazier, Tix, dan Barron (2004) mendapatkan hasil bahwa kepuasan hidup berkurang ketika penggunaan emotion focused coping yang digunakan secara meningkat dari masalah yang dirasakan, sehingga masalah yang dimiliki ketika belum terselesaikan mengakibatkan mahasiswa akan menjauhi penyebab masalah tersebut untuk mengatur tindakan dan perasaannya. 
Wachholtz, Lee, dan Kim (2016) mengemukakan bahwa semakin tinggi emotion focused coping seseorang karena terdapat penolakan dan menyalahkan diri menganggap rangsangan sekitar sebagai ancaman dan mempengaruhi cara rangsangan itu bekerja untuk mengendalikan emosi yang baik menuju penyelesaian masalah bahkan kepuasan hidupnya. Hamarat (2001) menjelaskan bahwa salah satu faktor yang mempengaruhi tingginya tingkat kepuasan hidup adalah usia. Faktor ini menyatakan bahwa semakin dewasa atau tua seseorang maka memiliki kepuasan hidup yang lebih tinggi pula dari pada usia yang lebih muda atau remaja, sehingga melalui penggunaan emotion focused coping terhadap masalah digunakan dengan baik maka akan memunculkan tindakan yang menjadikan seseorang dengan kepuasan hidup yang tinggi.

Karakteristik individu yang menunjukkan kepuasan hidup yang tinggi adalah orang memiliki tujuan penting di hidupnya dan berhasil dalam mencapainya, yang mempunyai orang terdekat seperti keluarga, dukungan teman sekitar, kegiatan yang dilakukan dapat bermanfaat untuknya dan mempunyai kesehatan yang baik (Schimmack, Diener, dan Oishi, 2002). Namun berdasarkan dari hasil penelitian pada kategori usia maupun angkatan 2015 dan 2016, menunjukkan tingkat kepuasan hidup yang rendah. Frisch (Sun dan Shek, 2010) telah menjelaskan bahwa orang yang memiliki kepuasan hidup yang baik akan mempunyai keyakinan, kemampuan sosial, coping yang efektif terhadap stres dan tindakan yang mengarah kepada tujuannya. Dengan kata lain, mahasiswa masih belum dapat mencapai kepuasan hidupnya ketika menghadapi masalah yang masih melibatkan emosi karena masih ada strategi coping lain yang bertujuan untuk berfokus pada penyelesaian masalah.

Zuhara, Muflikhati, dan Krisnatuti (2017) mengemukakan bahwa emotional focused coping digunakan untuk mengendalikan emosi atau mengurangi ketidaknyamanan ketika terjadi tekanan, jika digunakan dengan baik akan mengarahkan individu untuk mengikuti kegiatan keagamaan, berdoa dan beribadah, bercanda dengan keluarga atau teman serta menerima situasi sekarang sebagai tanggungjawab dalam melanjutkan pendidikan dan kehidupannya. Simsek (2011) menjelaskan bahwa kepuasan hidup dinilai sebagai tingkat emosi positif yang dialami. Oleh karena itu, penggunaan emotion focused coping pada mahasiswa, ketika menghadapi masalah dapat memiliki pemikiran yang ke arah positif meskipun cenderung melibatkan emosi sebagai jalan untuk menyelesaian masalah agar memunculkan kepuasan hidup yang baik.

Hal ini sejalan dengan penelitian yang dilakukan oleh Ryan (2013), Cabras dan Mondo (2017), bahwa individu yang menghadapi masalah kemudian menggunakan emotion focused coping dapat merasakan kepuasan hidup berdasarkan dari baik atau tidaknya penggunaan strategi coping dalam mengatur emosi ketika mendapat masalah. Pada mahasiswa, yang memiliki masalah dari hal akademik atau nonakademik untuk memenuhi tujuannya dalam berkuliah akan berpengaruh terhadap kepuasan hidupnya kedepan. Kepuasan hidup pada mahasiswa ialah merasa puas saat keperluan dan tujuan akademik mereka terpenuhi (Risdiantoro, Iswinarti, \& Hasanati, 2016). Bagi mahasiswa yang dapat menghadapi masalahnya dengan melibatkan emosi akan merasakan kepuasan hidupnya tersendiri, karena kepuasan hidup mahasiswa 
dapat ditingkatkan melalui perbaikan dalam keterampilan mengelola emosinya (Wong, Oei, Ang, Lee, Ng \& Leng, 2007).

Hasil penelitian mengenai kategorisasi gender dari variabel emotion focused coping didapat bahwa perempuan memiliki skor lebih tinggi dari pada laki-laki. Hasil penelitian ini didukung oleh penelitian sebelumnya yang dilakukan oleh Austenfeld dan Stanton (2004) bahwa perempuan dan laki-laki memiliki perbedaan yang signifikan terhadap pengendalian emosional dalam beberapa hal, karena perempuan menggunakan proses emosional dan ekspresi emosional yang lebih besar dari pada laki-laki.

Hasil penelitian terkait kategorisasi gender dari variabel kepuasan hidup didapat bahwa perempuan memiliki kepuasan hidup yang lebih tinggi daripada laki-laki. Hal ini sejalan dengan penelitian yang dihasilkan oleh Piontkowski (2011) bahwa perempuan memiliki pendekatan emosional yang tinggi, kepuasan hidup yang baik dan lebih sedikit mengalami tekanan. Adanya perbedaan hasil mengenai laki-laki dan perempuan terkait kepuasan hidup, dapat terjadi dari faktor-faktor lain seperti hasil akademik, dukungan sosial dan regulasi diri (Kandemir, 2014).

Berdasarkan hasil penelitian yang dijelaskan, untuk variabel emotion focused coping dengan variabel kepuasan hidup diketahui dari besar koefisien determinasi $\left(\mathrm{r}^{2}\right)$ yakni 0,120. Hasil tersebut menunjukkan bahwa variabel emotion focused coping memiliki sumbangan efektif sebesar $12 \%$ terhadap variabel kepuasan hidup, sedangkan $88 \%$ lainnya bisa dipengaruhi faktor lain yang mempengaruhi kepuasan hidup. Emotion focused coping bukan satu-satunya variabel yang dapat mempengaruhi kepuasan hidup pada mahasiswa. Weitten dan Lloyd (2006) menjelaskan bahwa terdapat faktor lain yang dapat mempengaruhi kepuasan hidup yang terdiri dari beberapa hal, yakni kesehatan, hubungan sosial, pernikahan, agama, pekerjaan, relialisme, kepribadian dan tingkat kesejahteraan.

Dengan pembahasan yang telah dijelaskan, bukan berarti pada penelitian ini tidak memiliki kekurangan serta keterbatasan. Berbagai keterbatasan dalam penelitian ini yaitu tidak teridentifikasi penyebab dari variabel emotion focused coping yang hanya memiliki skor $12 \%$, sehingga terdapat hubungan yang lemah antara emotion focused coping dengan kepuasan hidup pada mahasiswa. Keterbatasan selanjutnya mengenai alat ukur yang digunakan terkait skala kepuasan hidup yang mengembangkan item skala dari penelitian sebelumnya, sehingga item yang digunakan dalam penelitian harus disesuaikan kembali dengan penelitian yang dilakukan. Serta, keterbatasan terkait teori yang tidak langsung berkaitan, sehingga diperlukan kajian lebih mendalam mengenai hubungan antara variabel penelitian. Selain itu, penelitian ini menggunakan subjek mahasiswa Universitas Muhammadiyah Malang saja, sehingga tidak dapat di generalisasikan ke mahasiswa lainnya.

\section{SIMPULAN DAN IMPLIKASI}

Hasil dari penelitian menunjukkan adanya hubungan signifikan antara emotion focused coping dengan kepuasan hidup pada mahasiswa. Implikasi dari penelitian mengenai emotion focused coping terhadap kepuasan hidup dibagi dalam beberapa lingkup, pertama untuk kalangan mahasiswa lebih mengetahui terkait cara penyelesaian masalah, ketika menghadapi masalah sebagian besar mahasiswa 
menggunakan emotion focused coping terlebih dahulu untuk menata emosinya kemudian dilanjutkan ke tahap strategi coping berikutnya untuk penyelesaian sehingga dapat mencapai kepuasan hidupnya masing-masing.

Implikasi kedua untuk peneliti selanjutnya, yakni perlu adanya penelitian lanjutan mengenai orang-orang yang menghadapi masalah positif ke arah penyelesaian masalah yang sesungguhnya, karena emotion focused coping sebenarnya hanya sampai pada tahap regulasi emosi untuk menguatkan keadaan emosinya.

Implikasi ketiga untuk lembaga mahasiswa atau sejenisnya dapat memberikan pengarahan atau pelatihan terkait cara mengatur atau meregulasi emosi ketika menghadapi masalah sebagai mahasiswa yang memiliki permasalahan tersendiri di perkuliahan agar dapat mencapai kepuasan hidupnya, mengingat emotion focused coping merupakan strategi coping pertama yang digunakan ketika individu menghadapi masalah serta mahasiswa yang berada menuju dewasa awal sehingga akan mempengaruhinya dalam menyelesaikan masalah untuk mendapatkan kepuasan hidupnya.

\section{REFERENSI}

Achroza, F.H. (2013). Hubungan antara komunikasi interpersonal dosen pembimbing mahasiswa dan problem focused coping dengan stress dalam menyusun skripsi pada mahasiswa FKIP bimbingan dan konseling Universitass Muria Kudus. Skripsi. Universitas Muara Kudus, Kudus.

Adimas. (2016). Hubungan strategy emotion focused coping dan aggressive driving pada remaja. Skripsi. Universitas Muhammadiyah Malang.

Aldwin, C. M. \& Revenson, T. A. (1999). Does coping help ? A reexamination of the relation between coping and mental health. Journal Of Personality And Social Psychology, (53). 337348.

Amat, S., \& Mahmud, Z. (2009). Hubungan antara ketegasan diri dan kepuasan hidup dalam kalangan pelajar institusi pengkajian tinggi. Jurnal Pendidikan Malaysia 34 (2), 49-65.

Arnett, J.J. (2015). Emerging adulthood: the winding road from the late teens through the twenties. New York: Oxford University Press.

Austenfeld, J. L., \& Stanton, A. L. (2004). Coping through emotional approach: A new look at emotion, coping, and health-related outcomes. Journal of Personality, 72, 1335-63

Balkis, M. (2013). Academic procrastination, academic life Satisfaction and academic achievement: The mediation role of rational beliefs about studying. Journal of Cognitive and Behavioral Psychotherapies, 13(1), 57-74.

Baqutayan, \& Muhamed, S. (2012). A study on the College students' academic stress and its relation to their anxiety, time management and leisure satisfaction. Educational Leadership Journal.

Cabras, C., \& Mondo, M. (2017). Coping strategies, optimism, and life satisfaction among firstyear university student in Italy: gender and age differences. Higher Education. 75(4), 643 - 654. doi:10.1007/s10734-017-0161-x

Capan, B.E. (2010). Relationship among perfectionism, academic Procrastination and life satisfaction of university students. Procedia Social and Behavioral Sciences, 5, 1665-1671.

Chang, L., Mcbridge, C.C., Stewert, S.M., \& Au, E. (2003). Life satisfaction, self concept, and family relations in Chinese adoslecent and children. International Journal of Behavior Development 27 (2), 182- 189.

Chow, H.P. (2005). Assessing the determinants of life satisfaction in a Canadian university student sample. Alberta Journal of Educational Research, 51(1), 85-91. 
Civitci, A. (2015). Perceived stress and life satisfaction in college students: Belonging and extracurricular participation as moderators. Social and Behavioral Science. 205, $271-281$.

Coccia, C. \& Darling, C.A. (2014). Having the time of their life: College student stress, dating and satisfaction with life. Stress and Health. Publikasi online. doi: 10.1002/smi.2575

Deniz, M. (2006). The relationships among coping with stress, life satisfaction, decisionmaking styles and decision self-esteem: An investigation with Turkish university students. Social Behavior and Personality, 34, 1161-1170.

Diener, E. (1984). Subjective Well-Being. Psychological Bulletin, 95.

Diener, E. \& Suh, E. (1997). Measuring quality of life: Economic, social, and subjective indicators. Social Indicators Research, 40(1-2), 189- 216

Diener, E. D., Suh, E. M., Lucas. E. R., \& Smith, H. L. (1999). Subjective well-being: Three decades of progress. Psychological Bulletin,125, 276-302.

Diener, E., \& Biswas, D. R. (2008). The science of optimal happiness. Boston: Blackwell Publishing.

Diener, E., \& Diener, M., (2009). Cross-cultural correlates of life satisfaction and selfesteem. Journal of Culture and Well-Being 38, 71-91.

Duffy, R. D., Raque-Bogdan, T. L., \& Steger, M. F. (2008). Students in transition: Life satisfaction predictors of incoming college students. Doi: 10.1.1.295.3814

Eid, M. \& Diener, E. (2004). Global judgments of subjective well-being: Situational variability and long-term stability. Social Indicators Research, 65(3), 245-2.

Ehrlich, B. S., \& Isaacowitz, D. M. (2002). Does subjective well-being increase with age? Perspectives in Psychology, 20-26.

Essel, G., Owusu, P. (2017). Causes of students' stress, its effects on their academic success, and stress management by students. Thesis. Case study at Seinäjoki University of Applied Science, Finland.

Fajrina, F., \& Kurniawan, I. N. (2012). Studi deskriptif permasalahan kontrol diri dan kepuasan hidup mahasiswa (Laporan penelitian). Yogyakarta.

Farihah, F. (2014). Pengaruh self efficacy terhadap stres mahasiswa angkatan 2010 yang menyusun skripsi fakultas psikologi UIN Maulana Malik Ibrahim Malang. Skripsi. UIN Maulana Malik Ibrahim, Malang.

Frazier, P.A., Tix, A.P., \& Barron, K.E. (2004). Testing moderator and mediator effects in counseling psychology research. Journal of Counseling Psychology, 51(1), 115-34.

Frisch, M. B. (1998). Quality of life therapy and assessment in health care. Clinical Psychology: Science and Practice, 5, $19-20$.

Frisch. (2006). Quality of life therapy, applying a life satisfaction approach to positive psychology and cognitive therapy. New Jersey: John Wiley \& Sons, Inc. All right reserved.

Garcia. (2014). The affective profiles psychilogical well being and harmony: Environmental mastery and self acceptance predict the sence of a harmonies life. Journal Psycyatry and Psychology. Public Health.

Hamarat, E., Thompson, D., Zabrucky, K. M., Steele, D., Matheny, K. B., \& Aysan, F. (2001). Perceived stress and coping resource availability as predictors of life satisfaction in young, middle-aged, and older adults. Experimental Aging Research, 27(2), 181-196

Hestiningrum, E. (2012). Perbedaan emotional focused coping mahasiswa kost dengan mahasiswa yang tinggal dengan orang tua pada mahasiswa jurusan bimbingan dan konseling fakultas keguruan dan ilmu pendidikan Universitas Ahmad Dahlan Yogyakarta. Jurnal Psikopedagogia. 1 (2).

Higgins, C. A. \& Compeau, D. R. (1995). Application of social cognitive theory to training for computer skill. Information Systems Research. 6 (2), (118-143).

Holahan, C. J., Moos, R. H. (1987). Resource loss, resource gain, and depressive symptoms: A 10-year model. Journal of Personality and Social Psychology, (77): 620-629 
Huebner, E.S., Drane, J.W., \& Valois, R.F. (2000). Levels and demographic correlates of adolescent life satisfaction report. School Psychology International, 21, $281-292$.

Hurlock, E. B. (2009). Psikologi perkembangan. Jakarta: Erlangga.

Jenkins, S. R., Belanger, A., Connally, M. L., Boals, A., \& Duron, K. M. (2013). First-generation undergraduate students' social supprot, depression, and life satisfaction. Journal of College Counseling. 16.

Kandemir, M. (2014). Reasons of academic procrastination: Self-regulation, academic selfefficacy, life satisfaction and demographics variables. Procedia-Social and Behavioral Sciences, 152, 188-193. doi: 10.1016/j.sbspro.2014.09.179

Kang, T. K., \& Princy. (2013). Life satisfaction correlate of death anxiety among elderly. Indian Journal of Health and Wellbeing 4 (1), 121-124

Koivumaa, H, H., Honkanen, R., Viinamaki, H., Heikkila, K., Kaprio, J., \& Koskenvuo, M. (2001). Life satisfaction and suicide: a 20-year follow-up study. American Journal of Psychiatry, 158(3), 433-39.

Kusumawati, I. N. (2016). Pengaruh gratitude terhadap hubungan antara materialisme dan life satisfaction. Skripsi. Universitas Muhammadiyah Malang.

Lazarus, R. S. \& Folkman, S. (1984). Stress, appraisal dan coping. New York: Spinger.

Lewis, A. D., Huebner, E. S., Malone, P. S., \& Valois, R. F. (2011). Life satisfaction and student engagement in adolescents. Journal of Youth and Adolesence, 40, 249-262.

Li, M., Campbell, J. (2006). Cultural Adaption: A case study of Asian students' learning experiences at a New Zealand university. Edith Cowan University, International Conference.

Lim, C., \& Putnam, R.D. (2010). Religion, social network and life satisfaction. American Sociological Review 75 (6), 914-933.

Lounsbury, J. W., Saudargas, R. A., Gibson, L. W., \& Leong, F. T. (2005). An investigation of broad and narrow personality traits in relation to general and domain-specific life satisfaction of college students. Research in Higher Education. 46, 707-729.

Lukman, S. (2002). Manajemen keuangan perusahaan, edisi baru, cetakan ketujuh. Jakarta: PT. Raja Grafindo Persada.

Mappiare, A. (1982). Psikologi Remaja. Surabaya: Usaha Nasional.

Martikainen, L. (2008). The Many Faces of Life Satisfaction among Finnish Young Adults'. Journal of Happiness Studies, 10 (6), 721-737.

Maryam, S. (2017). Strategi coping: teori dan sumberdayanya. Jurnal. Konseling Andi Matappa. $1(2)$.

Park, N., Peterson, C., \& Seligman, M. E. P. (2004). Strengths of character and well being. Journal of Social and Clinical Psychology. 23(5), 603 - 619.

Piontkowski, S. (2011). First baby, first year: Gratitude and emotional approach coping as predictors of adjustment and life satisfaction during the transition to motherhood. Thesis. Faculty of the Graduate School of the University of Maryland.

Proctor, C. L., Linley, P. A., \& Maltby, J. (2008). Youth life satisfaction: A review of the literatute, Journal of Happiness Studies, 10, 583-630.

Pyhalto, K., Toom, A., Stubb, J., \& Lonka, K. (2015). Challenges of becoming a scholar: A study of doctoral students problems and well being.

Risdiantoro, R., Iswinarti, Hasanati, N. (2016). Hubungan prokrastinasi akademik, stres akademik dan kepuasan hidup mahasiswa. Seminar Asean 2nd Psychology \& Humanity, Psychology Forum UMM.

Ryan, K. (2013). How problem focused and emotion focused coping affects college students' perceived stress and life satisfaction. Submitted in Partial fulfilment of the requirements of the Bachelor of Arts degree (Psychology Specialization), at DBS School of Arts, Dublin. 
Saklofske, D. H., Austin, E. J., Mastoras, S. M., Beaton, L., \& Osborne, S. E. (2012). Relationships of personality, affect, emotional intelligence and coping with student stress and academic success: Different patterns of association for stress and success. Learning and Individual Differences, 22, 251-257.

Santrock, J.W. (2002). Life span development (perkembangan masa hidup, jilid 2). Penerjemah: Chusairi dan Damanik). Jakarta: Erlangga.

Santrock, J. W. (2007). Life span development, Perkembangan remaja, edisi kesebelas jilid 2. Jakarta: Erlangga.

Santrock, J. W. (2010). Life span development 13th ed, Perkembangan remaja, edisi ketigabelas jilid 2. Jakarta: Erlangga

Saptoto, R. (2010). Hubungan kecerdasan emosi dengan kemampuan coping adaptif. Jurnal Psikologi. 37 (1), 13-22.

Sarafino, E. (2002). Health psychology: A biopsychosocial interaction. New York: John Wiley \& Sons.

Sasaki, M., \& Yamasaki, K. (2007) Stress coping and the adjustment process among university freshmen. Counselling Psychology Quarterly, 20(1), 51-67.

Schimmack, U. (2008). The structure of subjective well-being. New York: The Guilford Press Second Edition, McGraww-Hill: New York.

Schimmack, U., Diener, E., \& Oishi, S. (2002). Life-satisfaction is a momentary judgment and a stable personality characteristic: The use of chronically accessible and stable sources. Journal of Personality, 70(3), 345-384. doi:10.1111/1467-6494.05008

Sekaran, U. (2006). Metode penelitian bisnis. Jakarta: Salemba Empat.

Simsek, E. (2011). The effects of organizational communication and personality traits on life satisfaction. Unpublished Doctoral Thesis. Eskisehir/Turkey: Anadolu Universitesi.

Siswoyo, D. (2007). Ilmu pendidikan. Yogyakarta: UNY Press.

Sousa, L., \& Lyubomirsky, S. (2001). Life satisfaction. In J. Worell (Ed), encylopedia of women and gender: Sex similarities and differences and the impact of society on gender, 2. San Diego : Academic Press.

Stevenson, A., \& Harper, S. (2016). Workplaces stress and the student learning experience.

Sugiyono. (2005). Statistik untuk penelitian. Bandung: Alfabeta.

Sugiyono, (2011). Metode penelitian kuantitatif, dan RED. Bandung: Alfabeta.

Sun, R. C. F., \& Shek, D. T. L. (2010). Life satisfaction, positive youth development, and problem behaviour among Chinese adolescents in Hong Kong. Social Indicators Research, 95(3), 455-474

Suryabrata, S. (2005). Metodologi penelitian. Jakarta: PT Raja Grafindo Persada.

Suldo, S. M., \& Shaffer, J. (2008). Looking beyond psychopatology: The dual-factor model of mental health in youth. School Psychology Review, 37, 52 - 68 .

Tamini, B. K., \& Ansari, A. (2014). Relationship of stress coping strategies and life satisfaction among students, International Journal of Psychology, 8(1), 156-165.

Valois, R. F., Zullig, K. J., Huebner, S. E., \& Drane, J. (2004). Life satisfaction and suicide among high school adolescents. Social Indicators Research, 66, 81-105.

Wachholtz, A., Kim, E., Lee, J. (2016). The effect of perceived stress on life satisfaction: The mediating effects of self efficacy. Chongsonyonhak Yongu. HHS Public Access. 23(10), $29-47$.

Weiten, W. \& Lloyd, M.A. (2006). Psychology applied modern life: Adjustment in the 21st century. (8th Ed.). California: Thomson Higher Education.

Widiyawati. (2001). Perbedaan kecerdasan strategi menghadapi masalah berdasarkan jenis kelamin pada mahasiswa Fakultas Psikologi Universitas Ahmad Dahlan. Skripsi. Yogyakarta: Fakultas Psikologi Universitas Ahmad Dahlan. 


\section{Cognicia}

Wong S.S., Oei, T.P.S., Ang, R.P., Lee, B.O., Ng, A.K. \& Leng, V. (2007). Personality, metamood experience, life satisfaction, and anxiety in Australian versus Singaporean students. Curr Psychol, 26, 109-120

Wright, T. (2003). Postgraduate research students: people in context. British Journal of Guidance and Conselling, 31(2), 209-227.

Wulandari, A. I. (2012). Permedaan emotion focused coping dalam hubungan interpersonal antar remaja yang mengikuti les musik klasik dan yang tidak mengikuti les musik klasik. Skripsi. Yogyakarta: Fakultas Psikologi Universitas Sanata Dharma.

Yusuf, S. (2012). Psikologi perkembangan anak dan remaja. Bandung: Remaja Rosdakarya.

Zhang, J., Zhao,S., Lester,D., \& Zhou,C. (2013). Life satisfaction and its correlate among students in China: a test of social reference theory. Asian Journal of Psychiatry. 452(4).

Zuhara, I., Muflikhati, I., \& Krisnatuti, D. (2017). Stressor, social support, coping strategy, stress, and life satisfaction of married woman student. Journal of Family Science. 2(1). 1, pp $1-1$ 